\title{
Neuropsychiatry Training in Nepal: Experiences of Trainees and Psychiatrists
}

\author{
Rai $Y^{1}$, Karki $\mathbf{U}^{2}$, Thapaliya $S^{3}$, Molina $\mathbf{R}^{4}$
}

1. Psychiatry Trainee, Essex Partnership University NHS Trust, Essex, UK 2. Child and adolescent Psychiatrist, Child and Adolescent Psychiatry Unit. Kanti Children's Hospital, Kathmandu, Nepal 3. Medical Training Initiative RCPsych Trainee, Kent and Medway NHS and Social Care Partnership Trust, Kent, UK 4. Department of Psychiatry, University Hospital Clinico San Carlos, Comillas University and Clinical Neuroscience Section of AEN, Madrid, Spain

E-mail *Corresponding author : raiyogesh39@ gmail.com

\begin{abstract}
Introduction: Training, practice and continuing professional development in neuropsychiatry and clinical neuroscience vary across different countries. However, little is known about the opinions of the Nepalese psychiatrists about the provision of neuropsychiatry training. This study evaluates the current training in neuropsychiatry and clinical neurosciences during the postgraduate psychiatry training and reflect on current practice.
\end{abstract}

Material And Method: The participants were psychiatrists (qualified and psychiatry residents). An online questionnaire using Survey Monkey electronic Platform was emailed with a uniform resource locator (URL).

Results: Sixty-four out of ninety-five participants responded with response rate of $65.3 \%$. Two-third of the respondents were qualified psychiatrists. The duration of neurology rotation ranged from 1 to 3 months and it was reported to be mandatory. Two-thirds reported that there is no clinical neuropsychiatry training during psychiatry residency. On a ten-point Likert scale (with 10 being the highest possible score), the participants rated their neuropsychiatry training as $5.16 \pm 1.84$ while they rated the necessity for further training in neuropsychiatry as 7.92 1 1.96. Two-thirds identified a lack of interest by the specialty society as an obstacle for the implementation of neuropsychiatry training for psychiatrists. More than half viewed that neuropsychiatry training to be incorporated into the existing psychiatry training scheme whereas three-fifths favoured a one-year specific training program in neuropsychiatry after completion of psychiatry training.

Conclusion: The current psychiatry training is inadequate to meet substantial neuropsychiatry training opportunities for a high proportion of psychiatrists in Nepal. This finding may be used to improve and standardize neuropsychiatry training in postgraduate psychiatry training.

Keywords: Neuropsychiatry, Psychiatry Training, Psychiatric Trainees, Nepal

\section{INTRODUCTION}

In Nepal, a three-year postgraduate psychiatry training/residency program (MD psychiatry) started in the Institute of Medicine (IOM), Kathmandu in $1997 .{ }^{1}$ Over the last two decades, there has been a substantial increase in the numbers of institutes providing postgraduate psychiatry training. Postgraduate training (residency) is run in 14 out of 20 medical colleges. However, training for MD (Doctor of Medicine) Psychiatry are provided in only 12 out of the 14 medical colleges. ${ }^{2}$ Moreover, postgraduate training program is not nationally standardised as there is no uniform curriculum and process of evaluation. ${ }^{3}$ There has also been an upsurge in interest in different subspecialties of psychiatry as evidenced by the establishment of child and adolescent psychiatry unit/clinic ${ }^{4}$, memory clinics, headache clinics and addiction units in the psychiatry department in teaching hospitals across the country.

Neuropsychiatry is not recognized as a subspecialty in Nepal and there is no formal training program. In Nepal, neuropsychiatry as 
a discipline is much misunderstood. At its core neuropsychiatry involves the understanding of neurological basis and treatment of the behavioural manifestations of neurological disorders. ${ }^{5}$ There is considerable overlap of psychiatric and neurological symptoms in many conditions and it is not uncommon for practicing psychiatrists to encounter these complexities during their clinical practice. Additionally, one also cannot ignore the significant proportion of comorbidities within the two disciplines of psychiatry and neurology. Psychiatry morbidities in neurology patients have been estimated at $40-55 \%$ in several European studies. ${ }^{6}$

Mental illness has been associated with stigma in many Asian countries, including Nepal. ${ }^{7}$ Patients and their families often prefer general physicians or neurologist to psychiatrists for mental health problems. There is a common trend among psychiatrists in developing countries like Nepal to designate themselves professionally as "Neuropsychiatrists". 8 While the exact reasons for this need to be researched, it can be speculated that such professional identity helps the psychiatrists to overcome the stigma and make themselves more appealing to people suffering from mental illness. Neurology and psychiatry are two distinct specialties in routine clinical practice. Neuropsychiatry is incorporated in the training curriculum of psychiatrists in Nepal and is examined in theory and the clinical examination as a short case. Psychiatry training also includes at least 1 to 3 months of neurology training. Psychiatric residents are also expected to achieve competencies in Neurology and the interpretation of electroencephalogram (EEG) and neuroradiology investigations during their training. Most psychiatry departments also offer EEG facilities in their institutions. Although it is widely recognized that all neurology/medical residents should have some knowledge and experience in neuropsychiatry, the provision of rotation in psychiatry for neurology/medical residents has not been established yet.

Psychiatry training is at a stage of evolution. With the rapid advancement in neurosciences, it has become more important than ever, for psychiatric residents to have a neuroscienceenhanced understanding of psychopathology, diagnosis, and treatment to ensure a holistic approach and provide better mental health care in the future. There is a substantial global recognition for the incorporation of neuroscience and neuropsychiatry in psychiatry training.9,10,11 Training, practice and continuing professional development in neuropsychiatry and clinical neuroscience vary across different countries. However, little is known about the opinions of the Nepalese psychiatrists about the provision of neuropsychiatry training and this is crucial to enhance the quality of the training and improve the future of mental health care in the country. The main objective of this study is to assess the current training in neuropsychiatry and clinical neurosciences during the postgraduate psychiatry training and reflect on current practice.

\section{MATERIAL AND METHOD}

The participants of this study were Nepalese psychiatrists (qualified and trainee residents). Participants were contacted through e-mail and an online questionnaire was sent via Survey Monkey with the URL. The objective of the study was mentioned on the web page of the URL. Ethical approval was not obtained for this study as the questionnaire was anonymised and confidentiality was maintained. Potential participants approached were all registered medical doctors in Nepal capable of providing informed consent by responding to the questionnaire, if they decided to take part in the study. However, the study has followed the principles of ethics as stated by Declaration of Helsinki, developed by the World Medical Association. ${ }^{12}$ Two reminder emails were sent, and responses were collected between $1^{\text {st }}$ January to $31^{\text {st }}$ March 2018.

The questionnaire was developed in English language in collaboration with the Spanish Clinical Neuroscience Section, Early Career Psychiatrists (ECPs) Section of the World Psychiatric Association (WPA), and European Federation of Psychiatric Trainees (EFPT). The survey evaluated the opinions of participants about their neuropsychiatry training opportunities. The questions were grouped into four main domains: a) sociodemographic details, b) neuropsychiatry training experience, c) barriers about neuropsychiatry training and d) opinions regarding neuropsychiatry training/practice. In this paper, we have 
confined our report to the results of Nepal. Survey results of other countries will be reported elsewhere. Data were analysed using Statistical Package for the Social Sciences (SPSS) version 23.0 for Windows. Results are described as frequency, percentages, and mean $\pm \mathrm{SD}$.

\section{RESULT}

Out of ninety-five, a total of 64 participants (qualified psychiatrists and residents) completed the survey with a response rate of $65.3 \%$. The results are summarised in Table 1, 2 and 3. The mean age was $32.59 \pm 4.33$ years and $71.9 \%$ $(n=46)$ were males. More than two-thirds of the respondents were qualified psychiatrists. The duration of neurology rotation ranged from 1 to 3 months and it was reported to be mandatory. Two-thirds reported that clinical neuropsychiatry training during psychiatry residency is not available. Epilepsy, dementia and functional symptoms were the three most common neuropsychiatric disorders encountered in clinical practice.

Twenty-two $(34.37 \%)$ of the respondents answered the open-ended questions. Some of the important comments given by the participants are as follows:

- Neuropsychiatry and neuroscience usually don't get much emphasis during residency training but in clinical practice, you find many overlapping and complex cases that are quite intriguing and confusing.

- Liaison between Neurology and Psychiatry and forum for mutual sharing between the two disciplines is a must in a developing country like Nepal.

- Neuropsychiatry still is not a separate field in Nepal. Psychiatrist calls themselves neuropsychiatrists to save themselves from stigma. So, there are no certified neuropsychiatrists.

- There needs to be a professional forum or society where neuropsychiatry discussion can be encouraged.

There is a need for awareness among young psychiatrists to realize the importance of special training in neuroscience and neuropsychiatry.
Table 1: Description Of Participants

\begin{tabular}{|l|l|l|}
\hline Characteristics & $\mathrm{n}(\%)$ \\
\hline \multirow{2}{*}{$\begin{array}{l}\text { Duration after } \\
\text { specialization (Years) }\end{array}$} & $1-5$ years & $35(54.7)$ \\
\cline { 2 - 3 } & 5-10 years & $3(4.7)$ \\
\cline { 2 - 3 } & 11-15 years & $4(6.3)$ \\
\hline Total & $1^{\text {st }}$ year & $42(65.7)$ \\
\cline { 2 - 3 } Year of residency & $2^{\text {nd }}$ year & $3(4.7)$ \\
\cline { 2 - 3 } & $3^{\text {rd }}$ year & $11(17.2)$ \\
\hline \multicolumn{2}{|l}{ Total } & $22(34.4)$ \\
\hline
\end{tabular}

Table 2: Description and evaluation of neuropsychiatry training $(n=64)$

\begin{tabular}{|c|c|c|}
\hline \multicolumn{2}{|l|}{ Characteristics } & $\mathrm{n}(\%)$ \\
\hline \multirow{3}{*}{$\begin{array}{l}\text { Duration of training } \\
\text { in neurology (in } \\
\text { months) }\end{array}$} & 1 month & $12(18.8)$ \\
\hline & 2 months & $35(54.7)$ \\
\hline & 3 months & $17(26.6)$ \\
\hline \multirow{2}{*}{$\begin{array}{l}\text { Mandatory training } \\
\text { in neurology }\end{array}$} & Yes & $64(100)$ \\
\hline & No & 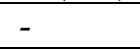 \\
\hline \multicolumn{3}{|c|}{ Type of neuropsychiatry training in Nepal } \\
\hline \multirow{5}{*}{\multicolumn{2}{|c|}{$\begin{array}{l}\text { Not received } \\
\text { Group discussions } \\
\text { Masters } \\
\text { Fellowships } \\
\text { Ongoing seminars, journal clubs, } \\
\text { and case presentations }\end{array}$}} & $42(65.6)$ \\
\hline & & $17(26.6)$ \\
\hline & & $2(3.1)$ \\
\hline & & $6(9.3)$ \\
\hline & & $6(9.3)$ \\
\hline
\end{tabular}

Commonly encountered neuropsychiatric disorders in clinical practice

Epilepsy

Dementia

Functional symptoms

Sleep disorders

Movement disorders

Brain injury

Cerebrovascular disease

Complex neuro disability

Rating of neuropsychiatry training $b$

Rating of necessity for further training in neuropsychiatry

Rating of relationship between neurologists and psychiatrists

Rating of necessity for better $8.79 \pm 1.63$ relationship between neurology and psychiatryc

$b, c$ These results are expressed as the mean $\pm S D$.

${ }^{b}$ Score on a ten-point scale 10 being the highest possible score

c Score on a ten-point scale with 0 indicating no necessity and 10 indicating greater necessity. 
Table 3: Opinions regarding neuropsychiatry training $(\mathrm{n}=64)$

\begin{tabular}{|l|l|}
\hline $\begin{array}{l}\text { Obstacles to implementation of } \\
\text { neuropsychiatry training }\end{array}$ & $\mathbf{n ~ ( \% )}$ \\
\hline $\begin{array}{l}\text { Lack of interest by the specialty society } \\
\text { Lack of time during residency }\end{array}$ & $44(68.8)$ \\
$\begin{array}{l}\text { Economic limitations } \\
\text { Political reasons }\end{array}$ & $18(28.1)$ \\
Lack of expert trainers & $16(25)$ \\
\hline $\begin{array}{l}\text { Best way for developing educational } \\
\text { resources for teaching clinical } \\
\text { neuroscience and neuropsychiatry to } \\
\text { psychiatry residents }\end{array}$ & $1(1.6)$ \\
\hline $\begin{array}{l}\text { During residency (without modifying the } \\
\text { duration of residency) }\end{array}$ & $34(53.1)$ \\
$\begin{array}{l}\text { After residency (1 year of specific training) } \\
\text { During residency (increasing duration of } \\
\text { residency) }\end{array}$ & $27(42.2)$ \\
$\begin{array}{l}\text { Before residency (1-2 years of common } \\
\text { training in neuroscience with } \\
\text { neurologists) }\end{array}$ & $10(9.4)$ \\
$\begin{array}{l}\text { Masters after residency } \\
\text { Only ongoing seminars }\end{array}$ & $7(10.1)$ \\
\hline
\end{tabular}

\section{DISCUSSION:}

The main finding of this study was that twothirds of participants reported that there is no clinical neuropsychiatry training during psychiatry residency. In this questionnaire, we specifically inquired about dedicated and structured neuropsychiatry experience. However, the participants also seem to have undergone exposure to neuropsychiatry cases which needs to be further explored. These shortfalls in clinical neuropsychiatry training programs for psychiatrists have also been highlighted in other countries. ${ }^{10,13}$ Only forty percent of American psychiatric residency training programs identified their program as providing specific training in neuropsychiatry. ${ }^{14}$ A national survey in the United Kingdom found that the majority $(73 \%)$ had no previous clinical training experience/ specialist interest session in neuropsychiatry. ${ }^{15}$ Although the neurology rotation for psychiatry residents in Nepal was mandatory, there was variation in the duration of the rotation which ranged from 1 to 3 months. Assessment of the standards of neurology training for psychiatry residents was beyond the scope of this questionnaire but it warrants to be explored in further research. It has been widely acknowledged that neurology training for psychiatry residents remains poorly standardized and clinical neurology experiences can have wide variations in terms of exposure and settings. ${ }^{16}$ Shalev and Jacoby ${ }^{16}$ suggested standardisation and evaluation of the full-time clinical neurology experience, longitudinal neuropsychiatry experience and collaborative didactic and clinical experience working alongside neurologists and neuropsychiatrists to improve neuropsychiatry skills among psychiatry residents. In our study, participants rated the relationship between psychiatrists and neurologists as $4.4 \pm 2.06$. It is encouraging to find that necessity of a better relationship between two specialties was rated highly (8.79 \pm 1.63$)$. Similarly, a survey of undergraduate medical school teachers, residents, and trainers in both neurology and psychiatry found widespread and high levels of support for educational links. ${ }^{17}$ Also, residents were keen to attend joint education, clinical and patient management sessions and outpatient clinics. Most psychiatry residency programs will need to establish close collaboration with their institutions' neurology departments to provide good clinical exposure and supervision of psychiatric residents to neuropsychiatry disorders.

On a ten-point Likert Scale, the participants rated their neuropsychiatry training as $5.16 \pm 1.84$ (with 10 being the highest possible score). It would have been prudent to explore the reasons for lower rating, but this is one of the limitations of this study. There is the possibility that lack of participants' interest or poor supervision during the rotation could have resulted in this response bias. However, it is encouraging to see their rating of a necessity for further training in neuropsychiatry was $7.92 \pm 1.96$ (with 0 indicating no necessity and 10 indicating greater necessity) indicating their awareness regarding their training. Several studies from the developed countries have also shown that neuropsychiatry training is lacking during their psychiatry residency program as discussed further. A study done by Fung et al ${ }^{18}$ found that only small proportion of residents and psychiatrists considered themselves to have a strong neuroscience knowledge base and most of them agreed on the need for further promotion of neuroscience education. In another survey, almost all residents agreed that there is a 
need for more neuroscience education in psychiatry residency training. ${ }^{19}$ Over threequarters of psychiatry trainees in the United Kingdom desired some knowledge and training in the field of neuropsychiatry. ${ }^{15}$ More than half of the respondents in our study, viewed that neuropsychiatry training should be incorporated into the existing psychiatry training program. These finding suggests that the postgraduate training curriculum might need to be updated to include structured neuropsychiatry training with adequate supervision to enhance the training experience. Additionally, three-fifths favoured a one-year specific training program in neuropsychiatry after completion of psychiatry training. A neuropsychiatry fellowship program can be initiated in collaboration with neurology departments for psychiatrists who are keen to develop a career neuropsychiatry subspecialty. In India, the National Institute of Mental Health and Neurosciences at Bengaluru has a one-year Postdoctoral Fellowship in Neuropsychiatry course which started in the year 2019. Eligibility for this fellowship is Doctorate of Medicine (DM) in Neurology or MD in Psychiatry or Diplomate of National Board (DNB) in Psychiatry. ${ }^{20}$

The most frequently perceived obstacles to the implementation of neuropsychiatry training in this study were lack of interest by specialist society, lack of time during residency and economic limitations. In contrast, survey data of psychiatry residency training directors from 2014 indicated that lack of neuropsychiatry faculty (39\%), lack of neuroscience faculty (36\%) and lack of neuroscience curricula for psychiatry residents were perceived as significant barriers to offering increased training in neuroscience and neuropsychiatry. ${ }^{21}$ Two-thirds of the respondents felt that challenges to incorporate neuropsychiatry training was the lack of interest from specialist society. Psychiatrists' Association of Nepal (PAN) ${ }^{3}$ being the flagship association of Nepalese psychiatrists can play an active role in the promotion of the implementation of neuroscience and neuropsychiatry training in psychiatry training. PAN can focus its scientific programs across these themes to fulfil the unmet needs of the contemporary psychiatrists. In the United Kingdom, the Royal College of
Psychiatrists (RCPsych) has initiated the Gatsby/Wellcome Neuroscience Project in 2016 to introduce a modern neuroscience perspective into psychiatrists' clinical work. ${ }^{22}$ The aim of the project is to integrate modern neuroscience in the syllabus for the Membership of Royal College of Psychiatrists (MRCPsych) examination and develop high-quality training opportunities for both trainees and trainers around the country. This project has identified the support and training needs of psychiatric educators teaching neuroscience as most of them are not experts in neuroscience. With this in hindsight, a series of regional training events called "Brain camps" are organized to train the trainers in neuroscience. In the United States, National Neuroscience Curriculum Initiative was launched in 2014 to create a platform of open resources that will help improve the teaching of neuroscience in psychiatry. ${ }^{23}$ It is highly encouraging that residents in Nepal already have neurology exposure during psychiatry training unlike in the UK. In addition to that, respondents to this survey were highly positive regarding further training in neuropsychiatry. Nepal can learn from the initiatives that have been undertaken in developed countries to update their training curriculum. There is an urgent need for an update of curriculum materials to be developed specifically aimed at teaching neuropsychiatry and neuroscience to psychiatry residents.

\section{CONCLUSION:}

This survey provides useful information regarding current training in neuropsychiatry and clinical neurosciences during the postgraduate psychiatry training in Nepal. The current psychiatry training may be inadequate to meet substantial neuropsychiatry training opportunities for a high proportion of psychiatrists and postgraduate psychiatry residents in Nepal. Proper implementation of available neurology rotation with incorporation of exposure to neuropsychiatry training can be a feasible option in Nepalese context to address this unmet training needs.

ACKNOWLEDGEMENT: The authors thank all the participants of this study for completing the survey. Finally, we thank the Early Career 
Psychiatrists (ECP) Section of the World Psychiatric Association (WPA) for this collaboration.

\section{FUNDING: None}

\section{CONFLICT OF INTEREST: None}

\section{REFERENCES:}

1. Shyangwa PM, Jha A. Nepal: trying to reach out to the community. International Psychiatry.2008; 5(2):36-8.

2. Karki U, Rai, Dhonju G. Sharma E, Jacob P, Kommu J et al. Child and adolescent psychiatry training in Nepal: early career psychiatrists' perspective. Child Adolescent Psychiatry and Mental Health. 2020;14:13. https://doi.org/10.1186/s13034-020-00319-5

3. Koirala NR. Psychiatrists' Association of NepalFuture of psychiatric services in Nepal- A mission and vision document. Journal of Psychiatrists' Association of Nepal. 2013;2(2):3-5.

4. Karki U, Dhonju G, Rai Y, Kunwar AR. Child and Adolescent Psychiatry in Nepal. WPA, Child and Adolescent Psychiatry Section's Official Journal. 2019;16;30-33

5. Cummings J, Hegarty A. Neurology, psychiatry and neuropsychiatry. Neurology.1994;44:209-13.

6. Agrawal N, Bhattacharya R. and Rickards R. Provision of neuropsychiatry services: variability and unmet needs. BJ Psych Bulletin. 2015; 39: 297-301.

7. Kudva K, El Hayek S, Gupta A, Kurokawa S, Bangshan L, Armas-Villavicencio $M$ et al. Stigma in mental illness: Perspective from eight Asian nations. Asia-Pacific Psychiatry. 2020; e12380. doi:10.1111/appy.12380

8. Shakya R. What's in a name? [Internet]. 2020 [cited 11 April 2020]. Available from: https://kathmandupost. com/news/2012-09-30/whats-in-a-name-240256.html

9. Bullmore E, Fletcher P, and Jones PB. Why psychiatry can't afford to be neurophobic. British Journal of Psychiatry. 2009; 194:293-5.

10. Mitchell AJ and Agrawal N. Training into neuropsychiatry: Is it time to reintegrate into mainstream psychiatry. Psychiatrist (Psychiatric Bulletin).2005; 29:361-4.

11. Ross DA, Travis MJ, Arbuckle MR. The future of psychiatry as a clinical neuroscience: why not now? JAMA Psychiatry.2015; 72:413-4.

12. WMA- The World Medical Association- WMA Declaration of Helsinki- Ethical Principles for Medical Research Involving Human Subjects [Internet]. Wma.net. 2020 [cited 20 June 2020]. Available from: https://wma.net/policies-post/wma-declaration-ofhelsinki-ethical-principles-for-medical-researchinvolving-human-subjects/

13. Price BH, Adams RD, Coyle JT. Neurology and psychiatry: closing the great divide. Neurology. 2000;54(1):8-14.
14. Duffy JD and Camlin H. Neuropsychiatric training in American psychiatric residency training programs. The Journal of Neuropsychiatry and Clinical Neuroscices.1995; 7 (3):290-4.

15. Conn R. A national trainee survey of Neuropsychiatry training experiences [Internet]. Core.ac.uk. 2020 [cited 11 April 2020]. Available from: https://core.ac.uk/download/pdf/76983272.pdf

16. Shalev D, Jacoby N. Neurology Training for Psychiatry Residents: Practices, Challenges, and Opportunities. Academic Psychiatry. 2018;43(1):89-95.

17. Schon F, MacKay A, Fernandez C. Is shared learning the way to bring UK Neurology and psychiatry closer: what teachers, trainers and trainees think. Journal of Neurology, Neurosurgery \& Psychiatry.2006;77:943-6.

18. Fung $L$, Akil $M$, Widge A, Roberts L, Etkin A. Attitudes Toward Neuroscience Education in Psychiatry: a National Multi-stakeholder Survey. Academic Psychiatry. 2014;39(2):139-146.

19. Fung L, Akil $M$, Widge A, Roberts L, Etkin A. Attitudes Toward Neuroscience Education Among Psychiatry Residents and Fellows. Academic Psychiatry. 2014;38(2):127-134.

20. National Institute of Mental Health and Neurosciences [Internet]. Current prospectus. [cited 11 April 2020]. Available from: http://nimhans.ac.in/wpcontent/uploads/2019/12/NIMHANS_Prospectus2020-21_Final-version.pdf

21. Benjamin S, Travis M, Cooper I, Dickey C, Reardon C. Neuropsychiatry and Neuroscience Education of Psychiatry Trainees: Attitudes and Barriers. Academic Psychiatry. 2014;38(2):135-140.

22. About the neuroscience project [Internet]. Royal College of Psychiatrists. 2020 [cited 11 April 2020].

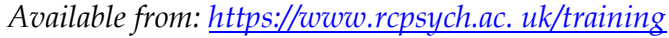
/neuroscience-in-training/about-the-neuroscienceproject

23. About [Internet]. www.nncionline.org. [cited 11 April 2020]. Available from: https://www.nncionline.org/ about/ 